\section{Comment to: Diagnostic Value of Serum Gastrin and Epidermal Growth Factor to the Gastric Ulcer Complicated with Upper Gastrointestinal Hemorrhage}

\section{Sir,}

We have read with great interest the article by Li et al. discussing the role and benefit of serum gastrin and epidermal growth factor (EGF) in predicting the early diagnosis of gastric ulcer and acute upper gastrointestinal bleeding (AUGIB). ${ }^{1}$ We believe that there are a few issues that need attention. As highlighted in the current literature, various scoring systems have been established, namely Rockall, AIMS65, Glasgow Blatchford and Progetto Nazionale Emorragia Digestiva score pertaining to AUGIB prediction. ${ }^{2}$ Among all, the Glasgow Blatchford score has the highest accuracy at predicting the need for an urgent endoscopy or outpatient management. ${ }^{2}$ The score consists of certain vital markers, in which, the important biochemical markers are serum haemoglobin and urea. We were wondering whether the addition of other serum markers can enhance the current well established predictive marker for AUGIB.

We believe that this method of "case-control" participant recruitment is subjected to selection bias and may overestimate the diagnostic accuracy. ${ }^{3,4}$ It would be more ideal for the authors to randomly select the subjects, or use a consecutive sampling method whereby all patients who were admitted for gastric ulcer in a specified period of time are recruited, irrespective of the outcomes. In Figure 1, it was also implied by the authors that the diagnostic accuracy of serum gastrin and EGF obtained from the ROC curves was able to predict gastric ulcer and AUGIB. We believe that this statement is inaccurate and may exaggerate the accuracy of both serum markers. Since both subject groups had gastric ulcer, the diagnostic accuracy values for serum gastrin and EGF in this study may only predict AUGIB in a population in which gastric ulcer is present, and not the general population. The more accurate title for Figure 1, in our opinion, would be "ROC curves of serum gastrin and EGF to predict AUGIB in patients with gastric ulcer," rather than "ROC curves of serum gastrin and EGF to predict gastric ulcer and acute upper gastrointestinal bleeding." This also applies to all other similar statements in the article.

\section{CONFLICT OF INTEREST:}

The authors declared no conflict of interest.

\section{AUTHORS' CONTRIBUTION:}

$\mathrm{FH}$ : Conceptualise the idea and drafted the letter. MAAR: Provided inputon statistical methods.
SSSAR: Involved in literature search.

All authors agreed on the final version of this letter.

\section{REFERENCES}

1. Li Y, Song Y. Diagnostic value of serum gastrin and epidermal growth factor to the gastric ulcer complicated with upper gastrointestinal hemorrhage. J Coll Physicians Surg Pak 2020; 30(12):1269-72. doi: 10.29271/jcpsp. 2020.12.1269.

2. Stanley AJ, Laine L, Dalton HR, Ngu JH, Schultz M, Abazi R, et al. International Gastrointestinal Bleeding Consortium. Comparison of risk scoring systems for patients presenting with upper gastrointestinal bleeding: International multicentre prospective study. BMJ 2017; 356:i6432. doi: 10.1136/bmj.i6432.

3. Lijmer JG, Mol BW, Heisterkamp S, Bonsel GJ, Prins MH, van der Meulen JH, et al. Empirical evidence of design-related bias in studies of diagnostic tests. JAMA 1999; 282 (11):1061-6. doi: 10.1001/jama.282.11.1061.

4. Whiting P, Rutjes AW, Reitsma JB, Glas AS, Bossuyt PM, Kleijnen J. Sources of variation and bias in studies of diagnostic accuracy: A systematic review. Ann Intern Med 2004; 140(3):189-202. doi: 10.7326/0003-4819-140-3200402030-00010.

Firdaus Hayati ${ }^{1}$, Muhammad Aklil Abdul Rahim ${ }^{2}$ and Syed Sharizman Syed Abdul Rahim ${ }^{2}$

${ }^{1}$ Department of Surgery, Faculty of Medicine and Health Sciences, Universiti Malaysia Sabah, Kota Kinabalu, Sabah, Malaysia

${ }^{2}$ Department of Community and Family Medicine, Faculty of Medicine and Health Sciences, Universiti Malaysia Sabah, Kota Kinabalu, Sabah, Malaysia

Correspondence to: Dr. Firdaus Hayati, Department of Surgery, Faculty of Medicine and Health Sciences, Universiti Malaysia Sabah, Kota Kinabalu, Sabah, Malaysia E-mail: m firdaus@ums.edu.my

Received: January 14, 2021; Revised: January 22, 2021; Accepted: January 25, 2021

DOI: https://doi.org/10.29271/jcpsp.2021.12.1522

\section{AUTHORS' REPLY}

Sir,

We are thankful to Hayati et al. for their interest in our article and certain positive comments on our study. ${ }^{1}$ It is true that the more accurate title for Figure 1 is "ROC curves of serum gastrin and EGF to predict AUGIB in patients with gastric ulcer." Upper gastrointestinal bleeding is one of the common clinical emergencies. ${ }^{2}$ It is important to makea rapid, early and accuratediagnosis for optimal treatment and better prognosis of patients with AUGIB. ${ }^{3}$ We found that the serum gastrin (GAS) and epidermal growth factor (EGF) had a certain value in predicting 
gastric ulcer with AUGIB; the predictive value of latter is greater than that of former. We acknowledge that this research method of "case-control" subject recruitment may be subject to selection bias and might overestimatethe diagnostic accuracy. Moreover, we also agree that the subjects of our study were patients with gastric ulcer and AUGIB, so the predictive values for serum GAS and EGF in our study only predict AUGIB in the population with gastric ulcer, and not the general population. For this reason, our study has some limitations, which are rightly pointed out by Hayati et al. ${ }^{1}$

\section{REFERENCES}

1. Hayati F, Rahim MAA, Abdul Rahim SSA. Comment to: Diagnostic value of serum gastrin and epidermal growth factor to the gastric ulcer complicated with upper gastrointestinal hemorrhage. J Coll Physicians Surg Pak 2021; 31(12).
2. Lau LHS, Sung JJY. Treatment of upper gastrointestinal bleeding in 2020: New techniques and outcomes. Dig Endosc 2021; 33(1):83-94. doi.org/10.1111/den.13674

3. Bardou M, Barkun AN . Editorial: How can we best promote the routine use of scores that are accurate at predicting outcomes in patients with upper gastrointestinal bleeding? Aliment Pharmacol Ther2020; 51:305-308. doi: 10. 1111/apt.15574.

Ying Li and Yuping Song

Department of Emergency, Beijing Jiangong Hospital, China

Correspondence to: Yuping Song, Department of Emergency, Beijing Jiangong Hospital, 100054, China E-mail: iuf535@163.com 